\title{
Resenha: uma história da recepção das ideias de Saussure e Benveniste no Brasil
}

\author{
Francisco Jeimes de Oliveira Paiva ${ }^{1}$
}

FLORES, Valdir do Nascimento. Saussure e Benveniste no Brasil: quatro aulas na École Normale Supérieure. São Paulo: Parábola Editorial, 2017.

Saussure e Benveniste no Brasil: quatro aulas na École Normale Supérieure, escrito pelo professor e pesquisador Valdir do Nascimento Flores, foi recentemente publicado pela Parábola Editorial. Este livro é organizado em quatro capítulos, cada um resultado de uma das conferências ministradas pelo autor na École Normale Supérieure - Paris/França. Ressaltese que esta obra oferece um panorama da história crítica e pessoal da recep̧̧ão das ideias de Ferdinand de Saussure e de Émile Benveniste no Brasil.

Essa história da recepção das ideias e teorias de Saussure e Benveniste é relatada ao longa da obra por um especialista na teoria desses teóricos no contexto das universidades brasileiras; Valdir Flores é Professor Titular em Língua Portuguesa do Instituto de Letras da UFRGS. Foi professor convidado na École Normale Supérieure, onde ministrou curso sobre a recepção de Saussure e Benveniste no Brasil, ministrando também aulas na Université de Paris III.

As palavras do autor na introdução apresentam claramente a importância das ideias saussurianas e benvenistianas no contexto das atividades acadêmicas atuais, sobretudo no Brasil, com o objetivo de reconhecer que "Saussure e Benveniste introduziram na linguística de seu tempo uma perspectiva que perdura até hoje e que se configurou como algo incontornável: o pertencimento da linguística às ciências do homem" (FLORES, 2017, p. 12). O pesquisador brasileiro nos chama ao entendimento de que os dois autores na contemporaneidade trazem uma desconfiança acerca do "alinhamento da linguística a um modo de fazer ciência que ignore o essencialmente humano, a capacidade simbólica de produzir sentido" (p. 12).

\footnotetext{
${ }_{1}^{1}$ Aluno do Mestrado Interdisciplinar em História e Letras na Universidade Estadual do Ceará. Especialista em Ensino de Língua Portuguesa e Literaturas e em Gestão Escolar e Práticas Pedagógicas. Licenciado em Letras pela Universidade Estadual do Ceará. Professor efetivo Seduc/CE.
} 
Esta edição foi organizada em quatro capítulos, oriundos das aulas ocorridas em conferências em Paris. Em suma, Valdir Flores propõe traçar um panorama da história crítica e pessoal da recepção das ideias de Saussure e Benveniste no Brasil. No primeiro capítulo "Recepção da linguística de Ferdinand de Saussure no Brasil", o autor apresenta uma abordagem explicativo-interpretativista, descrevendo historicamente o contexto vigente da recepção da Linguística de Saussure, interpretando-a em uma perspectiva subjetiva e analítica, a partir das experiências docentes e dos estudos de alguns pesquisadores sobre as ideias de Saussure e Benveniste em nosso país.

Flores não concebe a tradução do Curso de Linguistica Geral como algo tão polêmico, enfatizando que seja dada importância sobre a real necessidade de "avaliar a recepção da teoria entre nós" (FLORES, 2017, p. 16). Para isso, ele problematiza o próprio conceito de recep̧ão no viés terminológico, institucional e epistemológico, procurando interpretar a presença da linguística saussuriana na atualidade, além de fazer uma análise historiográfica da chegada de Saussure, considerando o passado e o momento atual da pesquisa linguística no Brasil.

De encontro à perspectiva anterior, Portela (2013) acentua que a divulgação do pensamento saussuriano no Brasil requereu essencialmente " $[. .$.$] compreender o modo como$ o pensamento de Saussure foi recebido no Brasil ao longo das últimas décadas [...]" (PORTELA, 2013, p. 15). Esta assertiva coaduna com as ideias de Flores (2017), expostas neste primeiro momento, em uma desafiante narrativa e interpretação pessoal, buscando desvendar uma série de dúvidas acerca da recepção das ideias linguísticas saussurianas no cenário brasileiro.

Em suma, Flores acentua o hiato existente entre a publicação do Curso de Linguística Geral (CLG) na França, em 1916, chegando esta obra no Brasil apenas em 1970, nada mais do que 54 anos depois. Nesse sentido, Flores (2017), fundamentado em Colombat, Fournier e Puech (2017 [2010]), esclarece detalhadamente como aconteceu essa recepção do Curso de Linguística Geral no Brasil, momento histórico ocorrido em um contexto diferente da recepção do CLG na França. Tais autores elucidam que ${ }^{2}$

[o]s linguistas do século XX tem relação com o saussurianismo por filiação assumida, formação ou reação. Ao que se acrescenta o fato de o CLG não ser

2 Uma história das ideias linguísticas, recentemente, publicado no Brasil em 2017, foi traduzido por Jacqueline Léon e Marli Quadros Leite. Embora Flores (2017) tenha adotado os originais, optou-se por citar a edição mais atual. 
propriedade exclusiva de linguistas: a partir do final da Segunda Guerra Mundial, o CLG é utilizado como um tipo de matriz em vista da "modernização" do conjunto das ciências humanas em círculos cada vez mais largos (COLOMBAT; FOURNIER; PUECH, 2017 [2010], p. 31, grifos dos autores).

Pode-se compreender que Flores (2017) tem assumido uma perspectiva pessoal, mas também detida em sua própria atuação docente e como pesquisador, objetivando a todo instante chamar os leitores à compreensão e ao debate acerca das leituras sobre Saussure. Por isso, o autor demonstra uma iniciativa de narrar esses pontos de vista sobre uma historiografia da linguística saussuriana, o que implica, portanto, uma demarcação de algumas singularidades acerca da importância dos estudos de Saussure no Brasil, mesmo porque "[a] presença de Saussure no Brasil é um acontecimento multifacetado que não se oferece facilmente à interpretação" (FLORES, 2017, p. 25, grifo do autor).

Vale destacar que o autor contextualiza ao longo deste primeiro capítulo o pensamento saussuriano entre nós através de uma leitura crítica, isso é possível em razão de três acontecimentos: a tradução dos Escritos de Linguística Geral, em 2004, a tradução da Introdução à leitura de Saussure, de Simon Bouquet, em 2000, e o aumento das relações institucionais e acadêmicas entre o Brasil e a França (FLORES, 2017, p. 26).

Nessa ótica, as pesquisas arroladas à "linguística saussuriana têm recebido, no Brasil, grande atenção por parte daqueles que buscam interpretar as ideias, recompor as teses de Saussure" (FLORES, 2017, p. 28). Vale destacar que os trabalhos circunscritos a Saussure podem ser vistos por uma leitura prospectiva, sendo ainda escassos. No entanto, temos pesquisas que estão alinhadas a uma retrospectiva da teoria saussuriana. Nesse sentido, Flores (2017, p. 35) considera que a recepção das teorias do mestre genebrino sucedidas "no Brasil não é comparável a recepção de Saussure na França”.

Vale lembrar que na apresentação "Por que ainda ler Saussure?”, de Fiorin, Flores e Barbisan (2013), organizadores de Saussure: a invenção da Linguística argumentam que

Num momento em que reaparecem, com força total, as teses biológicas para explicar os fatos humanos, num esvaziamento de sua dimensão social e cultural, Saussure é mais atual do que nunca. É necessário na resistência à desumanização das chamadas "ciências do homem". O linguista genebrino é daqueles autores que "quanto mais pensamos conhecer, por ouvir dizer, mais se revelam novos, inesperados e inéditos" (Calvino, 1998: 12). Além disso, Saussure, como todo clássico, serve para entender quem somos e aonde chegamos (Calvino, 1998: 16). Ele é fundamental para 
compreender a Linguística moderna (FIORIN; FLORES; BARBISAN, 2013, p. 9).

A ótica levantada por essa assertiva coaduna com as inquietações sugeridas por Flores (2017), uma vez que de forma concisa retorna essa discussão em torno das ideias saussurianas, problematizando o porquê da obra de Saussure não ter tanta receptividade no surgimento de uma disciplina sobre os estudos saussurianos, sobretudo nos cursos de Letras nas universidades do Brasil. Além disso, problematizando historiograficamente essa questão, o autor destaca que "os conteúdos linguísticos eram trabalhados de um ponto de vista histórico, nas disciplinas de língua portuguesa e filologia” (FLORES, 2017, p. 36).

Dessa forma, a leitura atenta desta obra nos permite perceber o contexto em que o Saussure de ontem pode ser evidenciado a partir dos fatos dos quais os estudos de lingua(gem) no Brasil foram oriundos, especialmente, de tradições normativas e filológicas, ao invés de uma tradição linguística sincrônica. A respeito dessas tradições, o autor ressalta que os estudos linguísticos no Brasil se apresentam a partir de três perspectivas: a gramática tradicional normativa, a filologia, a dialetologia (FLORES, 2017, p. 37).

No segundo capítulo "Recepção do pensamento de Benveniste no Brasil”, Flores (2017) procura sintetizar aos leitores a compreensão pessoal que tem acerca da recepção do pensamento de Benveniste, realizando tal propósito com contornos didáticos, pois o autor procura explicar a partir de dois momentos as ideias benvenistianas. $\mathrm{O}$ primeiro com foco na cronologia da chegada da obra deste linguista, sobretudo, nos anos de 1960, 1970, 1980 e 1990 no Brasil, mesmo que para Flores esse processo histórico de recepção das teorias de Benveniste tenha se dado de forma fragmentada e parcial no contexto das pesquisas brasileiras. Em outro momento, o autor, de forma mais crítica, objetivou desvendar a obra benvenistiana através de uma leitura com ênfase na historiografia linguística, apresentando as ideias deste linguista em consonância com o contexto de leitura e da assimilação do conjunto epistemológico da obra de Benveniste.

Nesse primeiro momento, Flores acentua que "Benveniste é um autor que ultrapassa limites disciplinares" (2017, p. 50), ou seja, a obra benvenistiana é muito maior do que alguns campos da linguística a colocaram-na, porque vai além do tratamento linguístico de temas específicos. De acordo com Flores, traçar um panorama da recepção das ideias de Benveniste no Brasil requer compreender que os “[...] estudos tratam de inúmeros aspectos da linguagem (morfologia, sintaxe, léxico, enunciação etc.) e estão em relação com várias 
áreas do conhecimento (filosofia, antropologia, psicanálise, literatura, história etc.)” (2017, p. $50)$.

Em outras palavras, o fato emblemático enfatizado pelo autor está na compreensão do próprio itinerário de leituras, por exemplo, do volume de Problemas de Linguística Geral (doravante PLG) de Benveniste no Brasil (de 1976) em relação à recepção das ideias benvenistianas na França (em 1966). Além disso, o autor ainda procurou compreender o itinerário de leituras (comparatista, "estruturalista" e teoria da enunciação) de como essas obras benvenistianas demandaram uma análise detida, sobretudo nos próprios textos do linguista quanto na apreensão comparativa das leituras feitas por seus comentadores.

Para tanto, Flores et al. (2008) já haviam mencionado que as características de escritura benvenistiana são correlatas à leitura epistemológica dos textos de Benveniste, sobretudo agora, em que situamos esta obra, que invoca uma série possibilidades de crítica e interpretação hermenêutica (FLORES, 2017, p. 48), as quais fornecem aos leitores outras percepções sobre a obra de Benveniste. Isso resultou na concepção benvenistiana a certa liberdade, configurando, pois, um ponto positivo, mas também um ponto negativo, na medida em que a obra de Benveniste "tem sido alvo de leituras que, muitas vezes, estão em diametral oposição aos princípios teóricos do autor” (FLORES et al., 2008, p. 31).

Ainda no capítulo "Benveniste no Brasil: a presença de últimas aulas”, Flores (2017) esclareceu a presença de Benveniste no Brasil e na França através de uma forte crítica e de uma concisa argumentação historiográfica da obra de Benveniste a partir das traduções das obras Problemas de linguística geral e de O vocabulário das instituiçoes indo-europeias, evidenciando, portanto, como a recepção das ideias benvenistianas se deu de forma "fragmentada, parcial e, em alguns casos, inadequada" (FLORES, 2017, p. 71).

Mais adiante, desenvolvendo os questionamentos e reflexões feitas na aula anterior, Flores, no terceiro capítulo, alarga a compreensão das ideias benvenistianas em duas partes, as quais o autor sistematiza sua leitura quanto à obra de Benveniste no Brasil. A primeira é reflexo de como ocorreu a inserção dos conceitos e noções de Benveniste pela linguística brasileira, que segundo Flores resultou em uma "configuração epistemológica estranha" (FLORES, 2017, p. 71) às reflexões do autor.

Por outro lado, desde 1990 já se pode falar em uma “segunda recepção das ideias de Benveniste no Brasil”, posto que, segundo Flores (2017), ocorreu um acontecimento que 
repercutiu na linguística brasileira, a tradução das Dernières leçons: Collège de France 1968 et 1969, de Émile Benveniste, publicada na França em 2012 e no Brasil em 2014. Flores argumenta que essa segunda recepção é resultado da preocupação dos especialistas brasileiros em ler Benveniste. $\mathrm{O}$ autor ressalta que

Há, hoje em dia, um reconhecimento de que os trabalhos de Benveniste no domínio da linguística geral modificaram fundamentalmente a paisagem das ciências humanas. Visando uma teoria de conjunto de linguagem, ele acabou se envolvendo com questões que, a princípio, estariam fora da cogitação de linguistas, questões essas relacionadas à arte, filosofia, sociologia, psicanálise, literatura. Suas proposições dizem respeito às relações entre linguagem, a sociedade e a subjetividade, se revelam de uma espantosa lucidez e começam a ser consideradas em toda a sua relevância (FLORES, 2017, p. 74-75).

Em outras palavras, é inegável o surgimento de uma convergência entre linguistas e pesquisadores de vários campos do saber que focam no estudo das linguagens, fazendo com que mais pesquisadores se debrucem sobre a obra de Benveniste e possam dar outra configuração epistemológica aos conceitos trabalhados pelo autor em suas pesquisas. Porém, isso não significa, conforme Flores, que a presença das ideias benvenistianas sejam melhores hoje do que antes, mas a verdade é que se intensificaram sobremaneira em muitos campos da linguística brasileira.

Enfim, as palavras e a defesa de Flores quanto ao viés antropológico da teoria da linguagem de Benveniste possuem um potencial teórico-metodológico que o próprio Benveniste não teve o ensejo de avaliar, logo fica patente a necessidade de "relê-lo de modo a compreender os aspectos que permitem ancorar a teoria em uma perspectiva que, mesmo incluindo a linguística, não se esgota nela” (FLORES, 2017, p. 85).

No último capítulo, "Prospecção de novas interpretações de Benveniste", percebese a preocupação de Flores em tecer uma prospecção de novas interpretações das ideias benvenistianas, posto que a repercussão das notas manuscritas feita por Chloé Laplatine em 2011 e a organização das últimas aulas de Benveniste no Collège de France, publicado em 2012 e traduzido no Brasil em 2014, ofereceram uma nova configuração e redimensionamentos da teoria de Benveniste em várias áreas de pesquisa (antropologia, filosofia, etc.) por outros linguistas e pesquisadores brasileiros.

Estas últimas aulas demonstram que no Brasil, primeiro houve uma recepção retrospectiva, resultantes dessas recentes publicações que fazem parte do conjunto da obra do 
autor, além de que em um segundo momento pode ser vista de maneira prospectiva por ser mais aberta para o estudo em outros campos da linguagem fora os que vem trabalhando os conceitos da teoria de Benveniste. De fato, o trabalho benvenistiano "não pode ser considerado como linguístico stricto sensu”, até por que Benveniste “[..] em suas últimas aulas, aborda as relações dos diferentes sistemas semiológicos e a escrita, o que, para mim, é um tema circunscrito à linguística” (FLORES, 2017, p. 92).

Levando em conta tudo que foi discutido, mesmo que em percursos de retrospecção e prospecção das teorias de Saussure e Benveniste no Brasil, é inegável a relevância e indicação de leitura de Saussure e Benveniste no Brasil: quatro aulas na École Normale Supérieure, de Valdir Flores, pois muitos pesquisadores munidos desta obra podem agora se debruçar sobre o conjunto de escritos e das obras seminais desses importantes estudiosos, não apenas do campo da linguística no Brasil, como de outras áreas de conhecimento, no sentido de recepcionar e propiciar várias releituras das ideias de Saussure e Benveniste no contexto brasileiro.

\section{Referências}

COLOMBAT, Bernard; FOURNIER, Jean-Marie; PUECH, Christian. Uma história das ideias linguísticas. Trad. Jacqueline Léon e Marli Quadros Leite. São Paulo: Contexto, 2017 [2010].

FIORIN, José Luiz; FLORES, Valdir do Nascimento; BARBISAN, Leci Borges (Org.). Saussure: a invenção da Linguística. São Paulo: Contexto, 2013.

FLORES, Valdir do Nascimento et al. Enunciação e gramática. São Paulo: Contexto, 2008.

PORTELA, Jean Cristtus. A divulgação do pensamento saussuriano no Brasil. Estudos semióticos, v. 9, no 2, Dez. 2013. Disponível em:

<https://dialnet.unirioja.es/descarga/articulo/5762333.pdf>. Acesso em: 14 fev. 2018.

Recebida em: 30/05/2018.

Aceita em: 29/06/2018. 